\title{
TO STUDY STRENGTH PARAMETERS OF CONCRETE USING
}

\section{BASALT FIBER}

\author{
Umadevi C.V ${ }^{1}$, Chirag ${ }^{2}$, Preejith Praveen ${ }^{3}$, Raksha Rao $^{4}$, Ashok $^{5}$ \\ ${ }^{I}$ Assistant Professor, Department of Civil Engineering, Srinivas University College of Engineering \&Technology, \\ Mangaluru, Karnataka, India \\ ${ }^{2} U G$ student, Department of Civil Engineering, Srinivas University College of Engineering\&Technology, Mangaluru, \\ Karnataka, India \\ ${ }^{3} U G$ student, Department of Civil Engineering, Srinivas University College of Engineering\&Technology, Mangaluru, \\ Karnataka, India \\ ${ }^{4} U G$ student, Department of Civil Engineering, Srinivas University College of Engineering \&Technology, Mangaluru, \\ Karnataka, India \\ ${ }^{5} U G$ student, Department of Civil Engineering, Srinivas University College of Engineering\&Technology, Mangaluru, \\ Karnataka, India
}

\begin{abstract}
Concrete plays a vital role as an important material in construction industry. Concrete acts as brittle material which is strong in compression weak in tension. To overcome the tensile properties of concrete generally various methods have been implemented .One of that is inducing fibers in concrete. Use of fibers in concrete increases the tensile properties in concrete. Basalt fiber is an inorganic material from volcanic rock and is comparatively new in the industry. Basalt fiber composites have been receiving increasing attention in civil infrastructures, due to their excellent mechanical and chemical properties and high cost-performance. This material may be used in construction industry for the structural elements and airport runways. In this project attempt has been made to study the strength parameters of concrete. The grade of concrete is M25. The fibers were added at percentage of 0 to 1.2 with an increment of $0.2 \%$. Characteristic strengths with different ratios of basalt fibers were studied for 7 days \& 28 days to find the optimum dosage of basalt fiber in concrete.
\end{abstract}

Keywords: - Basalt Fiber, Strength Parameters

\section{INTRODUCTION}

Construction is a major part of development plan of developing countries including India. To meet the large demand for infrastructure development, maintenance and life enhancement of structures are very important. Plain concrete possesses a very low tensile strength, limited ductility and little resistance to cracking. Conventional concrete doesn't meet many functional requirements such as impermeability, resistance to frost adequately. The presence of micro cracks at the mortar-aggregate interface is responsible for the inherent weakness of plain concrete. Because of the poor tensile strength, crack propagates with the application of load leading to brittle fracture of concrete. Micro cracks are formed in concrete during hardening stage. Natural disasters like earthquakes, cyclones, tsunami, etc. destroy the high rise buildings, bridges, monumental structures, world wonders. One such development has been two phase composite materials that is fiber reinforced concrete, in which cement based matrix, is reinforced with ordered or random distribution of fibers. Fiber in the cement based matrix acts as cracks arrester which restricts the growth of flaws in the matrix, preventing these from enlarging cracks under load which eventually cause failure. The weakness can be removed by inclusion of fibers in concrete. Basalt fibers are manufactured in a single-stage process by melting naturally occurring pure basalt rock. Basalt is a natural, hard, dense, dark brown to black volcanic igneous rock. It is the most common type in the earth's crust (the outer 10 to $50 \mathrm{~km}$ ). Its origins are at a depth of hundreds of $\mathrm{km}$ beneath the earth surface and it reaches the surface as molten magma. Basalt density ranges between $2700 \mathrm{~kg} / \mathrm{m} 3$ to $2800 \mathrm{~kg} / \mathrm{m} 3$.

\section{LITERATURE REVIEW}

Abhijeet b. revade et al [1] investigated on compressive and split tensile strength of chopped basalt fiber reinforced concrete of M20 grade concrete. Basalt fibers in low cost composites for civil infrastructure applications gives good mechanical properties like strength and lower cost predicted for basalt fibers. Basalt fiber has used as a cost effectively replace to fiberglass, steel fiber, polypropylene, polyethylene, polyester, aramid and carbon fiber products in many applications.

N. Gopi et al [2] conducted an experimental investigation of basalt fiber concrete. The workability of the concrete is greatly affected by the addition of fibers with the concrete and also imparts the use of super plasticizers to improve the 
workability but the addition of Basalt fibers with the concrete shows the same workability as the normal concrete and there is no need for any kind of super plasticizers to improve the workability. So in workability point of view addition of basalt fiber is not a defective one.

K. Sathes kumar et al[3] studied strength of concrete using basalt fiber. Basalt fiber offers more characteristics such as light weight, good fire resistance and strength. Basalt fiber having $0.5 \%, 1 \%$ showed an increasing compressive strength $5.64 \mathrm{Mpa}$ and $9.4 \mathrm{Mpa}$.

SuchitaHirde et al[4] investigated characteristic strength of M40 grade concrete with various proportions of basalt fiber. concluded that there was significant improvement in flexural and split tensile strength with the inclusion of basalt fibers in plain concrete. However maximum gain in the different strength of BFRC is found to be dependent upon the amount of fiber content.

Vijayaragharvan et al [5] analyzed the strength development of FRC with the addition of Basalt Fiber in Concrete and concluded that the compressive strength and flexural strength is comparatively increasing than any other traditional Fiber Reinforces Concrete. Since the compressive strength is increased by $12 \%$ and Flexure by $38 \%$, this material may be used in structural members like Beam Column joints and also in all kinds of tension and compression members.

\section{MATERIAL PROPERTIES}

A. Cement: ACC cement of 43grade which confirms to IS 8112-1976 was used. The physical characteristics of the cement are tested and have shown as below.

Table 1: Test Results of Cement

\begin{tabular}{|l|l|l|}
\hline Slno & Test Conducted & Results \\
\hline 1 & Normal consistency & $32 \%$ \\
\hline 2 & Initial setting time & $120 \mathrm{~min}$ \\
\hline 3 & Final setting time & $600 \mathrm{~min}$ \\
\hline 4 & Specific gravity of cement & 3.1 \\
\hline 5 & $\begin{array}{l}\text { Compression strength at } 28 \\
\text { days }\end{array}$ & $47.5 \mathrm{~N} / \mathrm{mm}^{2}$ \\
\hline
\end{tabular}

B. Fine Aggregate: The sand used in this experimental investigation was local river sand confirming to Grading Zone II of IS: 383-1970.The river sand was screened, to eliminate waste material and over size particles.

Table 2: Test Results of Fine Aggregates

\begin{tabular}{|l|l|l|}
\hline Sl no & Tests conducted & Results \\
\hline 1 & Specific gravity & 2.64 \\
\hline 2 & Water absorption & 0.50 \\
\hline 3 & Fineness modulus & 2.60 \\
\hline 4 & Sieve analysis & 2.64 \\
\hline
\end{tabular}

C. Natural Coarse Aggregate: 20mm down size coarse aggregates were considered for the project. The test on coarse aggregate was conducted in according with IS 23861963.

Table 3: Test Results of Coarse Aggregates

\begin{tabular}{|l|l|l|}
\hline Sl no & Tests conducted & Results \\
\hline 1 & Specific gravity & 2.74 \\
\hline 2 & Flakiness index & $25.5 \%$ \\
\hline 3 & Elongation index & $28.74 \%$ \\
\hline 4 & Water absorption & $1 \%$ \\
\hline 5 & Impact strength & $18.48 \%$ \\
\hline
\end{tabular}

D. Basalt Fiber: Basalt is typically brown, black, or red depending on its chemical content. Length and diameter of fiber is known by infra-spectrometer. Length $=8 \mathrm{~mm}$, Diameter $=16$ micron.

\section{EXPERIMENTAL INVESTIGATION}

The mix proportioning was done according to the Indian Standard IS 10262-2009[1].Cement, fine aggregate, coarse aggregate \& basalt fiber were properly mixed together in accordance with the ratio $1: 1.52: 2.78$ by weight and water was added and properly mixed together to achieve homogenous material. Water absorption capacity and moisture content correction were taken into consideration for mixing. Basalt fibers with different percentages $0.2 \%$, $0.4 \%, 0.6 \%, 0.8 \%, 1 \%, 1.2 \%, 1.4 \%$ are being added by the weight of cement. Cubes, cylinders and beams moulds were casted. Specimens were cured in water curing and hardened properties were determined for $7 \& 28$ days.

\section{RESULTS AND DISSCUSION}

\subsection{Compressive Strength Test}

The compressive strength test results on cubes for various different percentages of fibre is shown below. Results shows the increase in percentage of fibre content increases the compressive strength up to 1 percentage of fibre.At $1 \%$ the compressive strength was increased up to 2-3 Mpa compared to normal mix.

Table 4: Results of Compressive strength test for varying percentage of Fibre

\begin{tabular}{|l|l|l|l|}
\hline \multirow{2}{*}{$\begin{array}{l}\text { S1. } \\
\text { no }\end{array}$} & Percentage of basalt fiber & \multicolumn{2}{|l|}{ No of days } \\
\cline { 3 - 4 } & & 7 days & 28 days \\
\hline 1 & Normal mix & 22.45 & 33.99 \\
\hline 2 & 0.2 & 23.05 & 35.72 \\
\hline 3 & 0.4 & 23.65 & 36.12 \\
\hline 4 & 0.6 & 25.72 & 38.00 \\
\hline 5 & 0.8 & 26.92 & 38.37 \\
\hline 6 & 1.0 & 28.42 & 40.72 \\
\hline 7 & 1.2 & 28.14 & 40.04 \\
\hline 8 & 1.4 & 27.30 & 38.34 \\
\hline
\end{tabular}




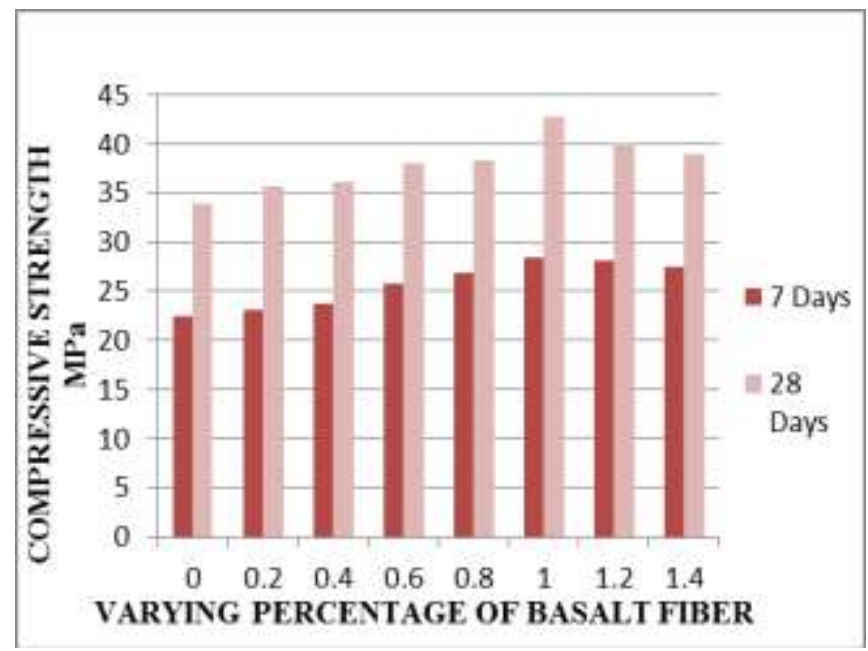

Graph 1: Comparison between Compressive strength of normal mix with varying percentage of basalt fiber.

\subsection{Split Tensile Strength Test}

The Split Tensile Strength test results on cylinders for various different percentages of fibre is shown below. Results shows the increase in percentage of fibre content increases the Split Tensile Strength up to 1 percentage of fiber.At 1\% the Split Tensile Strength has increased up to 34 Mpa compared to normal mix.

Table 5: Results of Split Tensile strength test for varying percentage of Fibre

\begin{tabular}{|l|l|l|l|}
\hline \multirow{2}{*}{$\begin{array}{l}\text { S1. } \\
\text { no }\end{array}$} & \multirow{2}{*}{$\begin{array}{l}\text { Percentage of basalt } \\
\text { fiber }\end{array}$} & \multicolumn{2}{|l|}{ No of days } \\
\cline { 3 - 4 } & & 7 days & 28 days \\
\hline 1 & 0 & 2.02 & 3.10 \\
\hline 2 & 0.2 & 2.42 & 3.75 \\
\hline 3 & 0.4 & 2.60 & 3.95 \\
\hline 4 & 0.6 & 2.96 & 4.37 \\
\hline 5 & 0.8 & 3.23 & 4.72 \\
\hline 6 & 1.0 & 3.42 & 4.93 \\
\hline 7 & 1.2 & 3.09 & 4.50 \\
\hline 8 & 1.4 & 2.82 & 3.93 \\
\hline
\end{tabular}

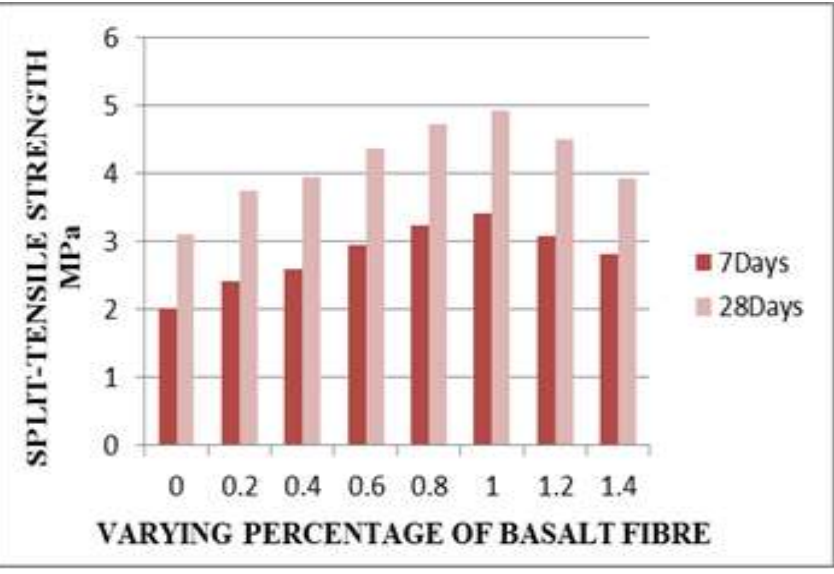

Graph 2: Comparison between Split tensile strength of normal mix with varying percentage of basalt fiber.

\subsection{Flexural Strength Test}

The Flexural Strength test results on beams for various different percentages of fibre is shown below.Results shows the increase in percentage of fibre content increases the Flexural Strength upto 1 percentage of fiber.At $1 \%$ the Flexural Strength has increased upto 5-6 Mpa compared to normal mix.

Table 6: Results of Flexural Strength test forvarying percentage of Fibre.

\begin{tabular}{|l|l|l|l|}
\hline \multirow{2}{*}{$\begin{array}{l}\text { Sl. } \\
\text { no }\end{array}$} & \multirow{2}{*}{ Percentage of basalt fiber } & \multicolumn{2}{|l|}{ No of days } \\
\cline { 3 - 4 } & & 7 days & 28 days \\
\hline 1 & 0 & 3.1 & 3.37 \\
\hline 2 & 0.2 & 3.7 & 5.80 \\
\hline 3 & 0.4 & 4.02 & 6.10 \\
\hline 4 & 0.6 & 4.35 & 6.84 \\
\hline 5 & 0.8 & 5.11 & 7.56 \\
\hline 6 & 1.0 & 5.72 & 8.20 \\
\hline 7 & 1.2 & 5.2 & 7.29 \\
\hline 8 & 1.4 & 4.52 & 6.03 \\
\hline
\end{tabular}

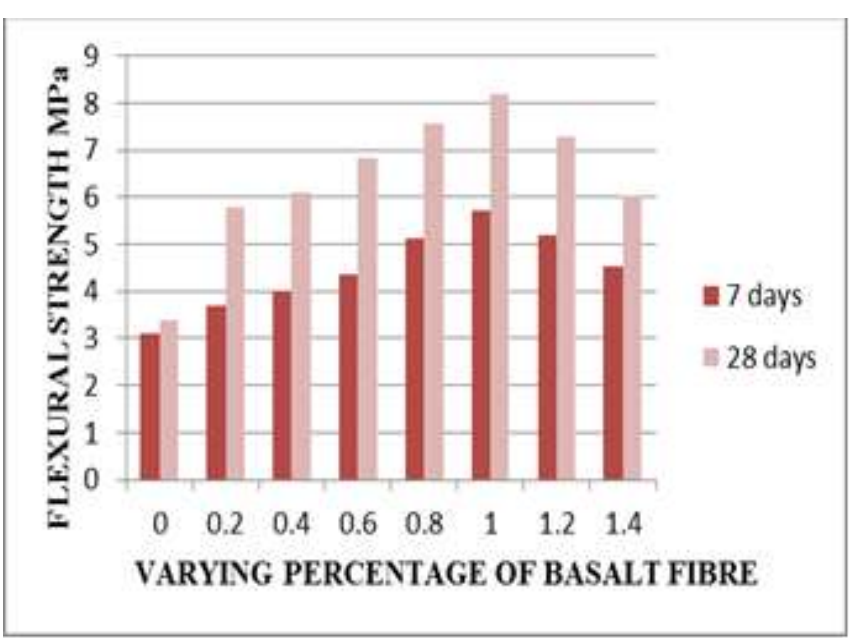

Graph 3: Comparison between Flexural strength of normal mix with varying percentage of basalt fiber.

\section{CONCLUSION}

- Addition of basalt fiber in concrete increased in flexural and tensile strength more than $30 \%$ compared to normal concrete.

- Nearly there is a $1-2 \mathrm{Mpa}$ increment in compressive strength and around 5-6 MPa in Split Tensile \& Flexural strength of concrete in basalt fiber reinforced concrete

- Increase in the percentage of fiber content in concrete increased the strength parameters of concrete up to $1 \%$, after $1 \%$ of basalt fiber there is a decrease in strength can be seen.

- Addition of basalt fiber in concrete mainly increases the tensile and flexural properties in concrete so basalt fiber can be used for structural member like beams and columns to sustain the load acting over it.

ACKNOWLEDGEMENT 
The authors are grateful to the Principal Dr.Shreeprakash B. helpingin every way during the course of the preparation. The authors also express gratitude to HOD Dr. Ramakrishna Hegdefor providing adequate facilities to complete this project.

\section{REFERENCES}

[1] Abhijeet B. Revade "Compressive and Split Tensile Strength of Chopped Basalt Fiber Concrete", International Research Journal of Engineering and Technolog (IRJET), Volume: 04, Issue: 06, June 2017, pp.347-351.

[2] N.Gopi, P.Baskar, B.Dharani and P.Abinaya "Experimental investigation of concrete with basalt fibre", International Journal of Emerging Technology in Computer Science \& Electronics (IJETCSE) ISSN: 0976-1353 Volume 21, Issue 1, APRIL 2016, pp.1115.

[3] K.Sathes Kumar, K.Tamilarasan, N.Sathish Kumar, Shirpy Thangam, Saranya, Vaisnavi, "Strength and Analysis of Basalt Fiber in Concrete", IJCRGG, Vol.10, pp.376-381, 2017.

[4] Suchita Hirde and Sagar Shelar "Effect of Basalt Fiber on Strength of Cement Concrete", International Journal of Current Engineering and Technology, 22 April 2017, Vol.7, No.2, pp.600-602.

[5] Vijayaraghavan, Dinesh, Nanthinipriya, Umabalachandran, "A Study on Strength Characteristics of Fiber Reinforced Concrete using Basalt Rock Fiber", International Journal of Engineering Trends and Technology (IJETT), Volume-45, Number-9 -March 2017, pp.471-475.

[6] Guidelines for concrete mix propotioning IS 102622009.

\section{BIOGRAPHIES}

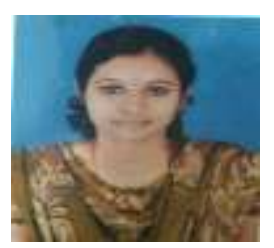

Umadevic.v is working as Assistant Professor in Department of Civil Engineering at Srinivas university college of engineering and technology. Mukka Mangaluru.

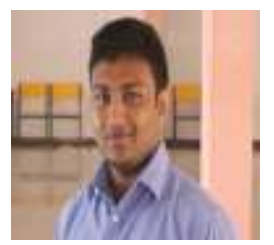

Chirag is an under graduate student in the Department of Civil Engineering at Srinivas university college of engineering and technology. Mukka Mangaluru.

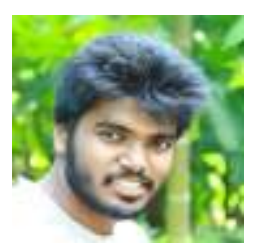

Prejith Praveen is an under graduate student in the Department of Civil Engineering at Srinivas university college of engineering and technology. Mukka Mangaluru.
Raksha Rao is an under graduate student in the Department of Civil Engineering at Srinivas university college of engineering and technology. Mukka Mangaluru.

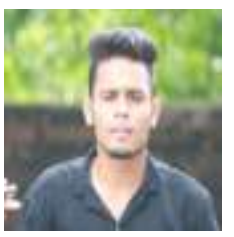

Ashok is an under graduate student in the Department of Civil Engineering at Srinivas university college of engineering and technology. Mukka Mangaluru. 